\title{
How monist is heterodoxy?
}

\author{
Rogier De Langhe*
}

\begin{abstract}
Some heterodox economists, most notably Tony Lawson, have come under suspicion of not being true pluralists, but 'strategic pluralists': their advocacy of pluralism is thought to be merely instrumental to a hidden monist agenda. This paper does not aim to judge the accused but rather to assess the accusations; the focus is on clarifying the notion of pluralism itself. First a paradox is found to lie at the core of scientific pluralism. Different responses to this paradox can be traced to different views on pluralism found in the literature. The resulting classification allows an analysis of the current controversy among pluralists and provides an understanding of the different aspects of the debate.
\end{abstract}

Key words: Pluralism, Epistemology, Heterodox economics, Orthodox economics, Philosophy of social science

FEL classifications: A10, B00, B40, B50

\section{Introduction}

Given the ubiquity of divergent views, it is indispensable to develop strategies to handle them without halting or distorting knowledge production. Of course, discrimination among views is often best dealt with by scholars from within the respective disciplines themselves. But given its common occurrence in virtually any science, an across-the-board story remains to be told. What are the causes of pluralism? Does it result from the nature of the world or from the way we investigate that world? How should scientists manage diversity? What does pluralism mean for science policy? What can a general analysis contribute to the solution of discipline-specific problems of theory choice?

Such general questions are not limited to the philosophy of science literature. Among others, heterodox ${ }^{1}$ economists have shown to be specifically keen on the notion of pluralism. So much so that some of them have come under suspicion (Van Bouwel, 2004; Sent, 2006; Giere, 2006) of what Ronald Giere has termed strategic pluralism. It refers to a pluralism advocated as 'primarily just a strategic move in the game of trying to dominate a field or profession. Those in the minority proclaim the virtues of pluralism in an effort to

Manuscript received 12 November 2007; final version received 29 July 2009.

Address for correspondence: Centre for Logic and Philosophy of Science, Ghent University, Blandijnberg 2, 9000 Ghent, Belgium; email: rogier.delanghe@ugent.be

* The author is a PhD fellow of the Research Foundation, Flanders (FWO). Thanks to Jeroen Van Bouwel, Erik Weber, Maarten Van Dyck, Wendy Olsen and Tony Lawson.

1 The usefulness of the heterodox-orthodox distinction could be called into question, as has been done by, e.g., Davis (2008) and Colander (2000).

(C) The Author 2009. Published by Oxford University Press on behalf of the Cambridge Political Economy Society. All rights reserved. 


\section{2 of 13 R. De Langhe}

legitimate their opposition to a dominant point of view. But one can be pretty sure that, if the insurgent group were itself ever to become dominant, talk of pluralism would subside and they would become every bit as monistic as those whom they had replaced' (Giere, 2006, p. 40). This would mean that the aims of heterodox calls for pluralism are actually no different from those of what Rob Garnett called paradigm warriors, i.e. those 'committed to the paradigmist approach, viewing heterodox economics as primarily a search for demarcation criteria that would render heterodox economics distinct from and superior to orthodox (mainstream) economics' (Garnett, 2006, p. 522).

Rather than getting tangled up in the controversy, the main concern of this paper lies with the very concept of pluralism itself. This contribution does not aim to judge the accused, but rather to assess the accusations. As such, the focus is on clarifying the notion of pluralism itself. First a paradox is found to lie at the core of scientific pluralism. Different responses to this paradox are then shown to lead to different views on pluralism found in the literature. Finally, the resulting classification allows an analysis of the current controversy among pluralists and provides an understanding of the different aspects of the debate.

\section{The paradox of pluralism}

If the most perplexing thing in the world is a lack of theory, the second most perplexing must be an abundance of it. The latter is what we witness in economics today. A broad range of schools strive for scholarly attention: neoclassical, social, feminist, institutionalist, Sraffian, Marxian, Austrian, post-Keynesian, etc. They not only differ in their answers but also in the way they frame their questions, rendering an unbiased comparison extremely difficult, if not impossible. This issue is clearly not economics-specific. Whether it is quantum mechanics, international relations theory or, indeed, even forest management, diversity is ubiquitous across the spectrum of the sciences. Even highly formalised sciences like logic and mathematics are divided into different schools of thought, debating fundamental issues such as the acceptability of certain kinds of inconsistencies or the existence of numbers.

Acknowledging the existence of a puzzling theoretical diversity is only a starting point. It leads directly to a much greater problem: the problem of how to deal with this diversity. ${ }^{1}$ There are numerous possible ways of answering this question such as monism or various kinds of pluralism. However, to tackle this issue systematically, I start with the two limiting alternatives: to accept all views simultaneously (syncretism) and to accept none (scepticism). Although these views are extremes and thus rarely held, they will prove to be useful beacons.

(i) Syncretism is an all-embracing position that comes down to accepting a conjunction of the alternatives. As there is something to be said for each of the contenders, judgement is suspended and all are kind-heartedly adopted as constituting the sum of our knowledge of the subject. The problem with this position is that it runs aground on its own inconsistencies. The answer to any question would be both yes and no, rendering syncretism ultimately uninformative.

(ii) Perhaps a more cynical response is the one which sees the alternatives as cancelling each other out. The sceptic stands perplexed when confronted with the multitude of views. While the syncretist still made a decision (albeit an empty one), the sceptic refrains

\footnotetext{
${ }^{1}$ I owe the distinction between syncretism, scepticism and relativism to Rescher (1993).
} 
completely. If all inquirers were to adopt this stance, science itself would come to a full stop. Their situation would be comparable to that of Buridan's ass: it starved while sitting between two equally appealing stacks of hay. Scepticism seems to be driven by a precautionary principle that leaves its advocates not only unspoiled but also in ignorance.

Both the sceptic and the syncretist have a safe but uninformative stance. The only alternative left is to make a selection after all. Now let us presume we do this in the most minimalist of ways, making a choice just for its own sake (e.g. by flipping a coin).

(iii) This leads to a very extreme form of relativism. ${ }^{1}$ The extreme relativist resigns himself to the necessity of choice, but denies the existence of any ground for picking one alternative over another. In the end the relativist is indifferent toward the alternatives; he only chooses because he thinks he has to. His commitment is contingent because it varies randomly, independent of good arguments for or against it. He has no tool whatsoever to convince others of his stance, except for his all-encompassing indifference. More importantly, he has no reason for a protracted exploration of a particular point of view, for the perspective he holds might change with every coin flip. An arbitrary choice is thus not sufficient, not for the scholar himself nor for his colleagues. He will need something more; some kind of a warrant. ${ }^{2}$

This first cut already enables us to derive a few useful hints on the development of an informative way to deal with theoretical diversity. From (i) and (ii) it was inferred that choice cannot be dispensed with. Additionally, from (iii) it was concluded that choice will somehow need to be warranted in order to avoid extreme relativism. A first general conclusion, valid for monism and pluralism alike, is that some kind of a warranted choice is needed when faced with divergent views.

For the monist this poses no problem. For the pluralist, however, this requirement leads straight into two fundamental problems, which lie at the heart of any kind of pluralism. The first problem is how equality is still possible in the face of making a warranted choice, the second problem is how warranted choice is possible in the face of equality. Corollaries of these problems give rise to two typical arguments against pluralism. If the first problem cannot be overcome, then it can be said that pluralism is self-defeating because it cannot claim its own truth lest it be inconsistent. If the second problem remains unsolved, the lack of warrant makes pluralism slide into an arbitrary 'anything goes'.

I will call this paradox between choice and equality the paradox of pluralism. ${ }^{3}$ Is this paradox the deathblow for pluralists? Not necessarily, but in the remainder of this paper it will be shown how different forms of pluralism are constituted by different ways to deal with it. As such it provides an excellent starting point for a classification of different forms of pluralism.

\section{Forms of pluralism}

In this section I will show how different ways of dealing with the paradox lead to different forms of pluralism. However, let us begin by characterising the complement: monism. Monism sees no reason for equality so the conflict with choice (and hence the paradox)

\footnotetext{
${ }^{1}$ Indeed, relativism need not be arbitrary, but in this case it is; hence the adjective 'extreme'. Again it must be stressed that these extreme views are only to be used as beacons, not as typifications of the (undoubtedly more subtle) views actually held by real scholars.

${ }^{2}$ A warrant has so far only been defined in a negative way, namely as anything that is not arbitrary. This is sufficient for this first cut.

${ }^{3}$ The 'paradox of pluralism' is an analogous to 'The Democratic Paradox' which Mouffe (2000) sees at the core of pluralism in political philosophy.
} 


\section{4 of 13 R. De Langhe}

does not appear. For the monist it is possible to attain a consensus on a coherent world view. The monist takes a clear stance and believes all others should take that same stance.

By contrast, pluralism is defined as a normative endorsement of a plurality of views and as such it is confronted with the paradox of pluralism. Because different forms of pluralism all need to deal with it, and do so in different ways, the paradox provides an excellent starting point for a classification of different forms of pluralism. The two versions of pluralism featured in this section, consensual and antagonist, differ in their assessment of the insurmountability of the paradox. In Section 5 antagonist pluralism will be further refined into agonist and antagonist pluralism.

Consensual pluralism acknowledges the existence of the paradox for now, but does not see it as insurmountable in principle. Consensualists tend to downplay the importance of the causes of theoretical diversity as presented in Section 1. For example Philip Kitcher spends an entire chapter of 'Science, Truth and Democracy' (Kitcher, 2001) to argue that the problem of underdetermination is less crippling than is often presented. Modest forms of the causes of diversity find their way into a much-used metaphor for this form of pluralism, namely that of maps. For the consensual pluralist, taking different perspectives is a matter of deciding on the basis of the question at hand, the practical purpose, which perspective needs to be taken under which circumstances. Depending on the purpose, different maps (subway maps, road maps, etc.) are chosen, without making an overall judgement of which map is the better map. Each depicts part of an underlying reality. The map metaphor is used by consensual pluralists like Ronald Giere and Philip Kitcher (e.g. Giere, 1999, ch. 4; Giere, 2006, ch. 4; Kitcher, 2001, ch. 5). It is used to present the view that different perspectives add to knowledge. Like maps, perspectives are chosen based on whatever practical interest we want our perspective to serve. Each perspective is only partially true and the different perspectives cannot be reduced to each other; however, the world they are representing and the true parts of the perspective add up to a consistent overall view. No one perspective can ever be totally true like no map can (there is 'no ideal atlas'; Kitcher, 2001 , p. 82), but dissent is set to vanish once the different maps are allocated to the different uses they can be put to. Philip Kitcher is very outspoken about this:

The pluralism I propose consists of the following claims: (1) there are many different systems of representation for scientific use in understanding nature; (2) there is no coherent ideal of a complete account of nature; (3) the representations that conform to nature (the true statements, the accurate maps, the models that fit parts of the world in various respects to various degrees) are jointly consistent; (4) at any stage in the history of the sciences, it's likely that the representations accepted are not all consistent. (Kitcher, 2002, pp. 571-2)

Ultimately different models will turn out to be complements rather than substitutes (however not coherent). As such, a pluralism is possible in which all worthy contenders in the diversity with which we are faced can be included: there is consensus without exclusion. Hence, for the consensualist the paradox of pluralism is not insurmountable. Dissent and discussion is not useful in itself but as a means to sort out all differences. While pursuing this ideal, the consensualist can never acquiesce in the difference; he cannot 'agree to disagree'. ${ }^{1}$ A similar position is found in the work of Jürgen Habermas. There are practical and empirical limitations that present obstacles to the realisation of the ideal discourse, but

\footnotetext{
1 The formal proof for this was delivered in a classic paper by Aumann (1976): 'If two people have the same priors, and their posteriors for a given event A are common knowledge, these posteriors must be equal. This is so even though they may base their posteriors on quite different information. In brief, people with the same priors cannot agree to disagree.'
} 
deliberation in an ideal speech situation is guaranteed to have a reasonable outcome. And John Rawls claims that a society containing different reasonable comprehensive doctrines can still become unified and stable through an overlapping consensus in which all worthy contenders (i.e. reasonable people) are included. In sum, consensualists grant that there are different viewpoints, but believe the paradox of pluralism can be surmounted by putting the differences in a well-ordered configuration: Rawls speaks of the well-ordered society (e.g. Rawls, 1993, p. 35) and Kitcher speaks of well-ordered science (Kitcher, 2001, ch. 10).

Antagonist pluralism holds that the nature of the paradox is not merely the result of practical limitations or limited cognitive abilities, but that it is, in principle, insurmountable. Whereas the consensualist tries to create a 'big tent' ${ }^{1}$ in which all worthy alternatives find their place and tends to minimise the causes of diversity as sketched in Section 2, the antagonist pluralist considers these causes to be more fundamental. Most importantly, the antagonist pluralist believes that the problem of theory choice is not exhausted by allocating different models to different uses or different domains. For example, Helen Longino remarks, in reply to Philip Kitcher, 'No sense, however, can be made by Kitcher of my suggestion that equally successful representations may be irreconcilable or noncongruent in any non-redundant way' (Longino, 2002, p. 575) As a consequence, it is impossible to reach a consensus without exclusion: because worthy alternatives are not necessarily complementary but can also be substitutes of each other a consensus sometimes involves the exclusion of alternative worthy views. Choice requires consensus and consensus requires exclusion, but exclusion goes against equality. Hence, the paradox between choice and equality strikes the antagonist with full force.

Conflict between (partial) substitutes is unavoidable and in contrast to the consensualist, it can be rational for the antagonist pluralist to 'agree to disagree'. Personal views based on different experiential backgrounds are not to be weeded out but are, to the contrary, constitutive of scientific activity. In this vein, Nicholas Rescher argues for the need to take a stance:

We have to see our standards in a hegemonistic light - as the uniquely right appropriately valid ones-because exactly this is what is at issue in their being our standards of authentic truth, value, or whatever. And of course those who would deny us this right-who say that we are not entitled to adopt those standards of ours - do no more than insist that it is by their standards (who else's?) inappropriate for us to have these standards, and thus are simply pitting their standards against ours. To insist that we should view our standards with indifference is to deny us the prospects of having any standards at all. Commitment at this level is simply unavoidable. (Rescher, 1993, p. 123)

To conclude this section, Table 1 rounds up the differences between consensualist and antagonist pluralism.

\section{Strategic pluralists}

Later sections will develop a more detailed picture of the different forms of pluralism, but the machinery developed so far is sufficient to address the issue of strategic pluralism.

\footnotetext{
${ }^{1}$ Some heterodox economists have warned that a pluralism of the consensual kind will likely require too much dilution of the different views it encompasses. Feminist scholars, for example, warn against being put in a post-Keynesian 'tent': 'Our suspicion is that accommodation in a big, or pluralist, Post Keynesian tent might extend only to those feminist scholars who use research methods consistent with a realist form of ontology, particularly critical realism. This might mean that research post structuralist or post modern research consistent only with a "strong social constructivist ontology" will be rejected by Post Keynesian.' (Austen and Jefferson, 2007)
} 


\section{6 of 13 R. De Langhe}

Table 1. A summary of the differences between consensualist and antagonist pluralism

Consensual pluralism

Impossible to 'agree to disagree'

Consensus without exclusion

Diversity without dissent

Different views are complements
Antagonist pluralism

'Agree to disagree'

No consensus without exclusion

Diversity and dissent

Different views can be substitutes

'Strategic pluralism' was introduced by the philosopher of science Ronald Giere. It refers to a pluralism advocated as:

... primarily just a strategic move in the game of trying to dominate a field or profession. Those in the minority proclaim the virtues of pluralism in an effort to legitimate their opposition to a dominant point of view. But one can be pretty sure that, if the insurgent group were itself ever to become dominant, talk of pluralism would subside and they would become every bit as monistic as those whom they had replaced. (Giere, 2006, p. 40)

This remark was a comment on an article by Esther-Mirjam Sent in the same edited volume (Sent, 2006). Sent herself (especially Sent, 2003) mentions the strategic character of the claims for pluralism by heterodox economists as an addition to a passage from Davis (1997) that appeared in the Salanti and Screpanti (1997) volume on Pluralism in Economics. This is where the roots of the concept of 'strategic pluralism' can be said to lie. In regard to the motivation of heterodox economists, Davis (1997, p. 209) claims that:

is not that their own theoretical approaches are also correct-a theoretical pluralist view-but rather that neoclassical economics is mistaken and misguided in its most basic assumptions, and that their own approaches remedy the deficiencies of neoclassicism-a theoretical monist view.

So according to Davis, some heterodox scholars are claiming their approach is superior, like a paradigm warrior, and this kind of pluralism is not in line with real pluralism, but rather with monism. Sent contrasts this with heterodox calls for pluralism and concludes that 'If heterodox economists employ appeals to pluralism strategically in an effort to achieve monism, they leave themselves vulnerable to criticism'. Some heterodox calls for pluralism are considered to be disingenuous because their commitment to pluralism is considered to be merely instrumental to the most anti-pluralist of goals, namely monism.

The thrust of the argument is as follows:

(i) Heterodox scholars claim to be pluralists.

(ii) Heterodox scholars are paradigm warriors because they claim to have a superior approach.

(iii) Paradigm warriors are monists.

(iv) Heterodox claims for pluralism are strategic because they call themselves pluralists but are in fact monists.

How sound is this argument? Arguments have been given only for premise (i) and (ii). The critics have only shown that heterodox economists such as Tony Lawson (e.g. 1997, 2003) are paradigm warriors but make the much stronger claim of 'strategic pluralism', which means that those heterodox scholars are not only paradigm warriors but monists who use 
pluralism instrumentally to achieve their monist aims. This only succeeds by making a tacit third assumption, namely that paradigm warriors are monists.

But are paradigm warriors necessarily monists? This conflation is understandable from the consensual point of view, for whom inclusivity ${ }^{1}$ of all worthy perspectives is key to their concept of pluralism. Excluding a view goes 'against the spirit of pluralism' because it is like denying the use of a subway map next to a road map. The consensualist tends to take premise (iii) for granted. However, the consensual view is just one way of dealing with the paradox of pluralism. A view on pluralism that still endorses a diversity of views but does not put much emphasis on inclusivity is the view of antagonist pluralist as sketched in the previous section.

As such, antagonist pluralism is the home of the 'paradigm warrior', characterised by Rob Garnett as those 'committed to the paradigmist approach, viewing heterodox economics as primarily a search for demarcation criteria that would render heterodox economics distinct from and superior to orthodox (mainstream) economics' (Garnett, 2006, p. 522). The paradigm warrior is to be classified as an antagonist pluralist and not as a monist. On the one hand the paradigm warrior takes a firm stance, but on the other hand the very idea of a paradigm implies that one single paradigm will never totally capture all knowledge. To the contrary, it is exactly the full development of its own logic that will eventually bring it down. Kuhn believed that crises of the dominant paradigm were mainly the result of its internal dynamic and not of rival paradigms.

At least for the scientific community as a whole, work within a well-defined and deeply ingrained tradition seems more productive of tradition-shattering novelties than work in which no similarly convergent standards are involved. How can this be so? I think it is because no other sort of work nearly so well suited to isolate for continuing and concentrated attention those loci of trouble or causes of crisis upon whose recognition the most fundamental advances in basic science depend. ... [N] ew theories and, to an increasing extent, novel discoveries in the mature sciences are not born 'de novo'. On the contrary, they emerge from old theories and within a matrix of old beliefs about the phenomena that the world does and does not contain. (Kuhn, 1977, p. 234)

As such the paradigm warrior takes a firm stance but does not believe everyone should take that same stance. This is the subtle but fundamental difference between the paradigm warrior and the monist. The monist aspires to nothing less than the monopoly for his point of view whereas the paradigm warrior does not aspire total theoretical domination. He does behave like a monist because he believes in the need to take stance and recognises the constitutive power of boundaries. It is a moderate form of exclusion, the kind of exclusion that the antagonist pluralist accepts as a constitutive part of scientific practice and finds crucial to delineate any kind of (political, scientific) identity.

It was John Davis' categorisation of parts of heterodoxy as 'monism' that gave rise to consensualist outrage and claims of disingenuity. As a result of the previous I argue that this categorisation is misguided. They are paradigm warriors, antagonist pluralists, not monists. To call this monism necessitates an additional leap from paradigm warrior to monist. To know whether heterodox scholars such as Tony Lawson are genuinely pluralist is ultimately an empirical matter and would involve knowledge of their underlying intentions. The only way to be sure would be to wait and see if they actually seize the monopoly when offered. But, in the meanwhile, it is to the critics to provide arguments for

1 The argument for inclusivity is indeed used in debates on pluralism in economics, e.g. Paul Davidson emphasises the virtues of compatibility and consequently rejects critical realism because 'The CR taxonomy ... makes impossible a serious "scientific" dialogue ... with the majority of the economics profession.' (Davidson, 1999, p. 129) 


\section{8 of 13 R. De Langhe}

this additional leap, which is only self-evident from the consensual point of view. As such I conclude that the criticism of disingenuous pluralism is exaggerated and my explanation for this exaggeration is the specific concept of pluralism from which this criticism is formulated, which leaves no room for a constitutive form of exclusion.

\section{Agonist and antagonist pluralism}

The previous section argued that a paradigm warrior is not necessarily a monist. But not being a monist does not automatically make one a pluralist. The argument that the antagonist pluralism of the paradigm warrior is not pluralism is brought forth by another voice in the debate, Jeroen Van Bouwel (2005). In order to see the subtleties of this side of the debate, the consensualist/antagonist classification from Section 4 needs to be extended: antagonist pluralism is refined into agonist and antagonist pluralism, yielding the tripartite classification of pluralism developed by Chantal Mouffe (e.g. 2000, 2005) between consensual, agonist and antagonist pluralism. This classification was applied to scientific pluralism by Van Bouwel (2009). Having pioneered the application of Mouffe's classification to scientific pluralism, he is aware of the different forms of pluralism discussed in this paper: he acknowledges that heterodox scholars such as Lawson are paradigm warriors and not monists and thus avoids the argument used in the previous section to counter the criticism of Davis, Sent and Giere. Instead, neither Jeroen Van Bouwel nor Chantal Mouffe consider antagonist pluralism to be a genuine form of pluralism.

Agonism and antagonism are similar in their differences with consensualism (see Table 1). Agonists agree with antagonists that exclusion and boundaries are unavoidable. For antagonist pluralism these boundaries are reified and constitute a fixed frontier between 'us' and 'them', between 'friends' and 'enemies'. Paradigms are rather homogenous entities of mutually supportive ontological, methodological and axiological assumptions. These rigid boundaries make possible a division of labour but are impediments to cross-paradigm discussion. Hence the antagonist pluralist is sceptical about the possibilities for communication. This stands in stark contrast with agonist pluralism, which conceives of the unavoidability of conflict and boundaries in a very different way. Chantal Mouffe, an agonist herself, considers substitutive views less homogenous and as such sees much more possibility for communication than the antagonist pluralist. This communication between alternative views is not one of negotiation but of contamination. In contrast to the incommensurability entailed by antagonism, she stresses the need for a common symbolic space where the unavoidable conflict can be 'sublimated' in a constructive way; opponents are not 'enemies' but 'adversaries'. In this view boundaries are, although ineradicable, constantly changing and challenged; 'the "them" is not a permanent outsider' (Mouffe, 2000, p. 56). In Mouffe's view, the paradox between choice and equality is a constructive tension: it is the driving force behind a debate that will never be resolved and whose resolution is not even desirable. In sum, whereas the antagonist pluralist reacts to the paradox of pluralism by acquiescing in the unavoidability of reconciliation and goes his own way, the agonist 'sublimates' the paradox by embarking on a perennial discussion.

Being an agonist himself, Van Bouwel's main concern is the lack of a symbolic space in which different views can oppose each other as 'adversaries' and not as 'enemies'. Tony Lawson does posit a divide between heterodoxy and mainstream and cements this in ontology. Van Bouwel disapproves of this rigid compartmentalisation and doubts Lawson's pluralist credential because, for Van Bouwel, 
a really pluralistic approach should engage in a conversation, in spelling out compatibilities and complementarities between the mainstream and the heterodox approaches (both sides should be engaged). The pluralism of Lawson risks leading us to an isolated diversity, to a lack of exchange of ideas. (Van Bouwel, 2005, p. 2)

A related worry of his is the antagonist pluralist's emphasis on homogeneity. The antagonist, with his reified boundaries, cannot leave his post without abandoning ship. For the more flexible agonist view piecemeal engineering is possible. Different parts of theories or paradigms (such as ontological, methodological and axiological assumptions) need not be mutually supportive to the extent that they cannot operate in each other's absence. Van Bouwel (2005) rejects this antagonist all-or-nothing winner-takes-it-all view:

The way in which Lawson develops guidelines for explanatory praxis and his rejection of the covering law model, give a good illustration of what form of pluralism Lawson is defending. By presenting mainstream economics as a monolithic unity as is done by Lawson, he invites critics to reject it en bloc.

The differences between agonist pluralism and antagonist pluralism are summed up in Table 2. Similar to the criticisms in the previous section, whether this detracts to ones pluralist credentials depends on the specific view on pluralism one holds. As such, it is a discussion among forms of pluralism and not between genuine and disingenuous pluralism. But in what sense can pluralist antagonism be called a genuine pluralism?

The antagonist sees alternative views as relatively homogenous entities, separated by reified boundaries. Discussion between rival views is difficult because of the 'paradox of outside criticism' (c.f. Rolin, 2009). Either standards for criticism are shared and outsider criticism is not possible because there are no real outsiders or standards are not shared and outsiders lack the standards to make their criticism heard. Lawson's (2006) criticism on the standard of mathematical modelling is a case in point. To reach the mainstream, he would paradoxically need to adopt, or at least not explicitly reject, the mathematical modelling standard himself. But refusing to do so makes him vulnerable to consensual and agonist criticism. ${ }^{1}$ In a case where agonist channels are de facto non-existent, the only way consensualism can be opposed is by taking an antagonist form. Although this in itself does not legitimise antagonist pluralism, it does make its occurrence understandable. How real this case is for economists is made clear by the following quote:

to get an article published in most of today's top rank economic journals, you must provide a mathematical model, even if it adds nothing to your verbal analysis. I have been at seminars where the presenter was asked after a few minutes, 'Where is your model?'. When he answered 'I have not got one as I do not need one, or cannot yet develop one, to consider my problem' the response was to turn off and figuratively, if not literally, to walk out. (Lipsey, 2001, p. 184)

Both agonism and antagonism acknowledge the role of power relations in science. But how can alternative views stand in a relation of contamination if there is a serious power imbalance? When this is the case, as heterodox scholars tend to argue is the case in economics, small and new perspectives risk being walked over if they do not take over a significant amount of the assumptions of the leading view. In such cases, an antagonist strategy might be preferable because of the infant industry protection it supplies. The thorough development of a certain stance, devising the best arguments for it and coming

\footnotetext{
1 'But it remains the case that these and all other widely sanctioned examples of ongoing change, diversity, novelty, complexity, evolution and multi-dimensionality, etc., are occurring within the framework of formalistic modelling. The insistence on mathematical-deductive modelling prevails in all cases; the essential feature of the recent and current mainstream remains intact.' (Lawson, 2006, p. 491)
} 


\section{0 of 13 R. De Langhe}

Table 2. Summary of the differences between agonist and antagonist pluralism

Agonist pluralism

Antagonist pluralism

Adversaries

Common symbolic space

Contamination

Boundaries necessary but not reified

Never-ending debate
Enemies

No common symbolic space

Incommensurability

Reified boundaries

Forcing discipline into diversity

up with critical tests might be necessary to develop it into a fruitful discussion partner in future agonist confrontations. Denying a perspective to this possibility would be an unequal treatment of different perspectives. Perspectives that were developed earlier had the time and the space to develop relatively unconstrained, while an agonist would let the later ones develop in tandem with already existent perspectives (making them vulnerable to unequal power relations). This bias would create a bias toward earlier developed theoretical frameworks and is only legitimate if an argument for some sort of epistemic value to temporal priority can be provided.

But even for older and bigger perspectives, an antagonist stance might not be condemnable at all times. An agonist stance leads to a dilution of perspectives and 'each of them changes the identity of the other' (Mouffe, 2000, p. 10), which impedes on 'the full development of their respective logics' (Mouffe, 2000, p. 10)). Although this leads to dialogue and mutual benefits, the integrity of the original perspective is lost. And why would the former under any circumstance be preferred to the latter? Some of the benefits of a stance might not reveal themselves until considerable specialised effort has been invested, just as the early stages of technological development do not reveal what these technologies will lead to in the long run (cf. Arthur, 1989). Moreover, a Kuhnian argument, it is exactly the absence of interaction between different paradigms that allows it to specialise and develop to its full potential because a framework can invest all available resources in itself. In what sense can this be called pluralist? Pluralism was defined as a normative endorsement of a plurality of views. The antagonist pluralist serves this cause not by being inclusive (consensualism) or communicative (agonism), but making sure enough well-developed alternatives are present to keep up the diversity of views that is a condition of possibility for pluralism.

The arguments provided suggest that agonism needs at least some people to work in an antagonist fashion under certain circumstances, not surprisingly the kind of circumstances reported by heterodox economists about their discipline. Agonism presupposes the prior existence of sufficiently diverse and developed perspectives. When these conditions are not met, antagonism is likely to be the ideal trailblazer for the agonist. The rigidity and homogeneity of the antagonist view makes the antagonist sceptical about the possibilities of discussion and thus set it apart from agonism. But this same rigidity and homogeneity allow for much more specialisation than agonism can achieve. To overcome the paradox of pluralism, instead of counting on agonist discussion, its comparative advantage lies with specialisation. Hence the antagonist addresses equality by holding that no single perspective will ever be able to deliver a complete answer (i.e. 'no consensus without exclusion', hence a paradigm warrior is not necessarily a monist) but still a stance is firmly taken, because it is exactly by taking an unambiguous stance that the benefits of specialisation will be reaped. For the pluralist antagonist, deep down it does not matter which stance is exactly taken. It is similar to the decision on which side of the road to drive. 
On which side we drive is equal, as long as we all choose to drive on the same side. Taking stance and being a focal point for other researchers is a solution to a problem of coordination in scientific communities. The strategy of the antagonist pluralist is to channel a community away from single-mindedness by providing an alternative focal point. The exclusion of parts of the mainstream and the advocacy of a division of labour within heterodoxy as advocated by Lawson (2006) is a nice illustration of this position. While agonism is pluralist by engaging in perennial discussion, the antagonist forces a discipline into diversity by using brute, focused, specialised force. In this sense, both agonist and antagonist pluralism are embodiments of a normative endorsement of a plurality of views and thus qualify as genuine forms of pluralism.

\section{Conclusion}

Are heterodox scholars such as Tony Lawson real pluralists? The above has shown that the label 'pluralist' can have at least three different meanings, each with their own response to the paradox of pluralism and a way to normatively endorse the plurality of views. Consensual pluralism believes in the possibility of respecting equality while still reaching consensus on choice. Agonist pluralism acknowledges the insurmountable tension between equality and choice and believes it to be constitutive of a perennial discussion. Antagonist pluralism also acknowledges the seriousness of the paradox, but the paradox of outside criticism makes the antagonist sceptical about the agonist calls for dialogue. Instead, it opts to pursue a plurality of views by forcing the community into diversity, creating alternative views where needed.

Having supplied a general framework to situate different forms of pluralism, it seems that different critics have each formulated their allegations from within their personal view of pluralism. Consensualists blame antagonists for not being inclusive and the agonists blame them for not engaging in discussion. But what puts these allegations in perspective is that all three pluralisms can be said to be no pluralism from the point of alternative forms of pluralisms. The consensual pluralist believes that interests or domain allocations exhaust epistemic indeterminacy. As such, once interests/domains are set, there is no more room for pluralism and one could ask if this is not covert monism. The consensualist can, in turn, reproach the agonist and the antagonist that they are not inclusive enough. This disagreement turns on the belief in the possibility of consensus without exclusion. The agonist, for his part, can be said to not fully endorse different perspectives, because it does not respect the integrity of the different views. But also antagonist pluralism can be said to be no pluralism. It is not inclusive and it does not leave much room for discussion and 'contamination'. While consensualists and agonists will, as individual scientists, have a pluralist attitude, the antagonist believes in specialisation ${ }^{1}$ and acquiesces in a pluralism at the level of the group or the discipline.

The main differences between the different forms of pluralism are indicated in Table 3. Interestingly, the different forms of pluralism offer different strategies for heterodox

\footnotetext{
1 Antagonism is similar to consensualism in that it allows for common frameworks and hence enables profound specialisation. But whereas for the consensualist this specialisation is merely an unintended consequence of the assumed complementarity of different views, it is a strong motivational factor for the antagonist. The antagonist holds that no perspective will ever be able to deliver a complete answer; it stands together with agonism on the idea of 'no consensus without exclusion'. But still a stance is firmly taken, albeit just for the sake of it, in order to reap the benefits of specialisation. In the same way as it does not matter on which side of the road we all drive, as long as we all drive on the same side. Taking stance and being a focal point for other researchers is a solution to a problem of coordination in scientific communities. It should thus come as no surprise that Lawson (2006) advocates a division of labour within heterodoxy.
} 


\section{2 of 13 R. De Langhe}

Table 3. Summary of the main differences between the different forms of pluralism

\begin{tabular}{lccc}
\hline & Consensual & Agonist & Antagonist \\
\hline Inclusive & Yes & No & No \\
Consensus without exclusion & No & Yes & Yes \\
Dissent & No & Yes & No \\
Contamination & No & Yes & No \\
Individual pluralism & Yes & Yes & No \\
Retaining perspectival integrity & Yes & No & Yes \\
Reification of boundaries & No & No & Yes \\
\hline
\end{tabular}

scholars on how to deal with the mainstream. In recent years numerous scholars have put forth such strategies. The classification of pluralism presented in this paper could be, in principle, used to classify these proposals and associate them with the form of pluralism they are formulated from. The consensualist would seek a well-ordered economics by attempting to organise a division of labour between mainstream and heterodoxy. By agreeing on the interests or domains different research programmes aim to cover, it is believed that disputes will eventually be resolved. The agonist calls for heterodox scholars to never cease discussion and keep 'agonist channels' open. It is not the final resolution that counts, but the debate itself that is seen as a constitutive force for scientific development. An antagonist strategy creates a different perspective to force the discipline into a diversity of views.

So is Tony Lawson a pluralist? It now becomes obvious why the focus of this paper had to be on assessing the accusations and not on judging the accused. The judgement itself is quite uncontroversial: Lawson's relation with the mainstream, more specifically its a priori insistence of mathematical modelling, is one of antagonism (although within heterodoxy he is a consensualist pluralist; cf. the division of labour within heterodoxy envisioned by Lawson, 2006). However, this judgement only acquires meaning after answering the much more important question of whether or not antagonist pluralism is a genuine form of pluralism. The present paper has argued that there are circumstances under which antagonist pluralism is a legitimate form of pluralism and that it is indeed a tenable position given the situation heterodox economists allegedly find themselves in.

Finally, I hope to have made a contribution to a more refined understanding of pluralism that might inform future contributions on the topic. For that matter, Rob Garnett is still right when he noted that 'Pluralism remains an undertheorized topic in economics ... (Garnett, 2006, p. 527)

\section{Bibliography}

Arthur, B. 1989. Competing technologies, increasing returns, and lock-in by historical events, The Economic fournal, vol. 99, no. 394, 116-31

Aumann, R. 1976. Agreeing to disagree, The Annals of Statistics, vol. 4, no. 6, 1236-9

Austen, S. and Jefferson, T. 2007. Feminist and post-Keynesian economics: challenges and opportunities, Cambridge fournal of Economics, Advance Access published November 23, doi: 10.1093/cje/bem046

Colander, D. 2000. The death of Neoclassical economics, fournal of the History of Economic Thought, vol. 22, no. 2, 127-43

Davis, J. 1997. Comment, pp. 207-11 in Salanti, A. and Screpanti, E. (eds), Pluralism in Economics, Cheltenham, Edward Elgar 


\section{How monist is heterodoxy?}

Davis, J. 2008. The turn in recent economics and return of orthodoxy, Cambridge fournal of Economics, vol. 32, 349-66

Davidson, P. 1999. Taxonomy, communication, and rhetorical strategy, fournal of Post Keynesian Economics, vol. 22, no. 1, 125-9

Garnett, R. 2006. Paradigms and pluralism in heterodox economics, Review of Political Economy, vol. 18 , no. $4,521-46$

Giere, R. 1999. Science without Laws, Chicago, Chicago University Press

Giere, R. 2006. Perspectival pluralism, pp. 26-41 in Kellert, S., Longino, H., and Waters, K. (eds), Scientific Pluralism, Minnesota, Minnesota Studies in the Philosophy of Science

Kitcher, P. 2001. Science, Truth, and Democracy, Oxford, Oxford University Press

Kitcher, P. 2002. Reply to Helen Longino, Philosophy of Science, vol. 69, December, 569-72

Kuhn, T. 1977. The Essential Tension, Chicago, University of Chicago Press

Lawson, T. 1997. Economics and Reality, London and New York, Routledge

Lawson, T. 2003. Reorienting Economics, London and New York, Routledge

Lawson, T. 2006. The nature of heterodox economics, Cambridge Fournal of Economics, vol. 30, 483-505

Longino, H. 2002. Reply to Philip Kitcher, Philosophy of Science, vol. 69, December, 573-7

Lipsey, R. 2001. Successes and failures in the transformation of economics, fournal of Economic Methodology, vol. 8, no. 2, 169-202

Mouffe, C. 2000. The Democratic Paradox, London, Verso

Mouffe, C. 2005. On the Political, London, Routledge

Rawls, J. 1993. Political Liberalism, New York, Columbia University Press

Rescher, N. 1993. Pluralism: Against the Demand for Consensus, New York, Oxford University Press

Rolin, K. 2009. Scientific knowledge: A stakeholder theory, pp. 62-80 in Van Bouwel, J. (ed.), The Social Sciences and Democracy, Basingstoke, Palgrave Macmillan

Salanti, A. and Screpanti, E. (eds), 1997. Pluralism in Economics, Cheltenham, Edward Elgar

Sent, E. 2003. Pleas for Pluralism, Post-Autistic Economics Review, issue 18, February, article 1, available at http://www.paecon.net/PAEReview/issue18/Sent18.htm [date last accessed 15 September 2009]

Sent, E. 2006. Pluralism in economics, pp. 80-101 in Kellert, S., Longino, H. and Waters, K. (eds), Scientific Pluralism, Minnesota, Minnesota Studies in the Philosophy of Science

Van Bouwel, J. 2004. Explanatory pluralism in economics. Against the mainstream? Philosophical Explorations, vol. 7, no. 3, 299-315

Van Bouwel, J. 2005. Towards a framework for pluralism in economics, Post-Autistic Economics Review, issue 30, March 2005, article 3, available at http://www.paecon.net/PAEReview/ issue30/VanBouwel30.htm [date last accessed 15 September 2009]

Van Bouwel, J. 2009. The problem with(out) consensus: The scientific consensus, deliberative democracy and agonistic pluralism, pp. 121-142 in Van Bouwel, J. (ed.), The Social Sciences and Democracy, Basingstoke, Palgrave Macmillan 